\title{
Mental health and COVID - 19: an action plan
}

Giulia Simonetti, $\mathrm{PhD}^{\mathrm{a}}$, Carmela losco, $\mathrm{PhD}^{\mathrm{b}}$, Gianfranco Taruschio, $\mathrm{MD}^{\mathrm{c}}$
a. Department of Medicine and Surgery of University of Naples Federico II, Naples, Italy
b. Public Education, High School, Italy
c. Villa Baruzziana, Private Hospital, Bologna, Italy

Corresponding author

Giulia Simonetti PhD, Adjunct Professor of Psychology at Department of Medicine and Surgery of University of Naples Federico II, Naples, Italy and Private Practice of Psychologist and Psychoterapist, Italy

ORCID: https://orcid.org/0000-0001-8306-6133; Phone: 0039 3349070061; e-mail: simgiu@ hotmail.it.

\begin{abstract}
Since January, the disease caused by the Sars Cov-2 virus has spread and following pandemic. In a few months, the virus is seriously affecting the health systems of the various countries of the world and placing people in difficult psychological conditions. Few scientific resources on mental health have been published but still no one has proposed an action plan to cope the future psychological problems. This manuscript suggests a plan to easily frame the priorities of mental health area related to COVID-19 to be taken into consideration, which should be disseminated and be known by all health professionals and also by the major administrators of public health.
\end{abstract}

\section{Introduction}

SARS-COV-2 virus has spread in China since December 2019 (World Health Organization, n.d.-a), leading to the first outbreak of the current epidemic. This novel viral strain belongs to Coronaviridae Family and is capable to generate a disease (COVID-19) with serious respiratory complications and serious implications that can lead to death. At the end of January 2020, also Italy was affected by this epidemic, now defined pandemic by World Health Organization (World Health Organization, n.d.b), and the first preventive governmental measures were implemented to contain the spread of the virus. In mid-February it was necessary to enforce serious containment measures until reaching March 8, the date on which the whole country was defined in "quarantine" with a decree of the President of the Council of Ministers. Schools, universities, pubs, bars and businesses not considered essential necessities have been closed. The whole population is required to stay indoors.

The World Health Organization has declared the pandemic. Some researchers have focused attention on the psychological conditions of populations affected by the virus ((National Health Commission of China., n.d.; Xiang, Yang, \& Li, 2020; Sijia, Wang, Jia, Nan, \& Tingshao, 2020).

Since COVID-19 epidemic has spread recently, current literature about this issue is still updating, with few published papers on PubMed so far.

We are in an emergency situation, a calamity never experienced before. Diagnostic and Statistical Manual of mental disorders (DSM 5) establishes the first criterion necessary for making a diagnosis of Post-Traumatic Stress Disorder (PTSD) as "exposure to real death or death threat, serious injury" in one of the following ways: i) to have direct experience of the traumatic event; ii) to attend directly 
to the traumatic event that happened to others; iii) to become aware of a traumatic event that happened to a family member or to a close friend; iv) to have repeated experience or extract exposure to raw details of the traumatic event (American Psychiatric Association, 2013, pp. 271-272). Based on the above, we can affirm that the whole world population runs the risk of developing a PTSD. Obviously, in order to make this diagnosis, it is necessary to suffer from other psychological manifestations as well, but it must be said that at least one criterion is already satisfied for the entire world population. Luckily, over the years, we have developed effective techniques to treat psychiatric disorders including PTSD but it is necessary, at this time, to have a clear action plan to address the situation in the best way.

This consideration brings to think about how to properly frame and cope the situation of mental state of the population; for this purpose, it can be useful to refer to the Taylor and Frazer's (1981, p. 72) model on the classification of victims.

\section{Action plan by categories}

Coordination of an action plan would be not possible without an accurate detection of different categories of people at risk. Specific interventions should be addressed to proper categories.

First of all, it is necessary to consider the psychological conditions of people who directly suffer the impact of the event, I refer to COVID-19 patients (Duan \& Zhu, 2020). These people, given the contagiousness of the virus, cannot take advantage of face-to-face psychiatric and psychological counselling, living their disease condition in almost total isolation. Therefore, be it would appropriate to promptly set up a remote counselling service (by tablets or smartphones) for patients with mild symptoms and psychological intervention for people with symptoms in remission that don't need to be intubated. Furthermore, in this category, it is necessary to consider people who have a positive history of psychiatric disorder and to evaluate drug interactions appropriately. An Italian study provided some information on this issue (Ostuzzi et al., n.d.). Note that particular attention must be paid to the interaction between COVID 19 and psychotropic drugs which can generate respiratory depression. Finally, we must consider the possibility, according to some studies (Baig et al., n.d.; Li, Bai, \& Hashikawa, 2020), of the virus to influence the central nervous system. For this reason, close attention should be paid to the overall mental health of patients with COVID-19.

Secondly, people close to the deceased and survivors must be considered. These people are grieved for their loved ones and experienced the fear of being infected. They also were unable to assist their loved ones and must respect a quarantine of at least 14 days and can't participate to the ritual of burial with consequently stop of process for the elaboration of loss. For these people, it is necessary to consider all the psychological implications typical of the loss and condition of isolation due to the quarantine as well as the fear of contagion and the possibility of developing the survivor syndrome. Even for this category of people, a serious psychological support service must be readily available also with new remote psychological counselling such as the structured letter therapy suggested by Xiao (2020).

After these, rescuers and health workers must be considered. From some data published by Chinese researchers, anxiety and stress levels among healthcare professionals are very high (Huang, Han, Luo, Ren, \& Zhou, 2020; Kang et al., 2020; Chen et al., 2020). For this category, it is necessary to immediately provide face-to-face psychological support or remote psychological counselling using videocall system or similar technologies to allows them to keep on working and prevent the development of serious psychiatric symptoms related to a PTSD. 
We must also consider who for pre-critical features can react by developing a short- or long-term psychological disorder. Nevertheless, thousands of both school and University students are staying at home without any physical interaction each other, with high risk to lose the community sense developed before. It is necessary to remember that there are people in particularly vulnerable conditions such as children, elderly people, prisoners, pregnant women and people living in quarantine with violent partners. Furthermore, it must be considered that there are many psychiatric patients at risk of contagion and the management of these patients must be coordinated and managed adequately by the operators and institutions. It is necessary to schedule a reorganization of outpatient visits for psychiatric patients and specialist psycho-educational interventions to dispel what is happening in the world from psychiatric patients, as already suggested by some researchers (Liebrenz, Bhugra, Buadze, \& Schleifer, 2020; Wang et al., 2020).

Finally, we must count who could have been a victim affected by COVID 19 or who feels involved for indirect reasons. In general, we must consider the whole population involved (Shigemura, Ursano, Morganstein, Kurosawa, \& Benedek, 2020). The first studies show an increase in symptoms related to depression and anxiety in the general population (Sijia, Wang, Jia, Nan, \& Tingshao, 2020). Furthermore, the quarantine conditions to which all Italian citizens are invited, as well as those of other countries of the world, can generate symptoms related to different emotional states and not least those typical of PTSD (Brooks et al., 2020).

Precisely on the basis of the considerations made, the first mental health professionals to work in these situations are emergency psychologists and EMDR (Eye Movement desensitization and reprocessing) specialists.

Both the World Health Organization and the EFPA (European Federation of Psychologists' Associations) have prepared some guidelines for dealing with this emergency. In different countries, because of heterogeneous situation, many services have been activated such as autonomous initiatives, telephone support lines, spontaneous online psychological counselling services (Asmundson \& Taylor, 2020; Zhou, 2020). The National Council of the Order of Italian Psychologists (CNOP) always calls for compliance with the Code of Ethics of psychologists and primarily invites emergency psychologists to work in this situation. Therefore, initiatives implemented by non-mental health professionals are not recommended. It is always advisable to have adequate preparation to deal with this type of emergency. It is therefore advisable for all countries to organize psychological support services for all the victims mentioned in a short time and to coordinate the professionals involved in health services in an orderly manner. In case of need, also mental health professionals not properly trained yet could be employed. These professionals could carry out specific training courses on emergency psychology and coronavirus in a short time, as prepared by WHO and in Italy by CNOP, EMDR Italia, Red Cross and other scientific subjects (World Health Organization, n.d.-c; CNOP, n.d.d).

All these interventions should be managed by instruments useful to coordinate the actions effectively. We suggest the use of a global digital platform that collects all data and all proposal searchable by users, in order not to lose any interventions. Furthermore may be useful to implement the "basic psychologist system" (primary care psychologist) in cooperation with General Medical Doctor that works for general population. In this way no one will be forget and every citizen will have a reference psychologist. This project in Italy has been successfully tested in different cities without ever being implemented on the whole national territory. Interventions like this would guarantee an organized and regulated public service for whole population's mental health care.

For healthcare personnel and hospitalized patients, on the other hand, it would be necessary to strengthen the resources already present in the treatment institutes (Figure 1).

\section{Conclusion}


It should be considered that the potential psychiatric diseases that can develop as a result of COVID 19 could have a long-term negative economic impact if not treated properly (Silva, Resurrección, Antunes, Frasquilho, \& Cardoso, 2018). Psychological reactions during emergencies can influence people's behaviours and cause damage to the health and economic organization. Notably, if on the one hand social media is helping people to live in quarantine conditions, on the other hand the disclosure of fake news and alarming videos can facilitate the increase of dysfunctional psychological states. In fact, anxiety about health, named by Asmundson and Taylor (2020) "coronaphobia", can push people to seek more medical reassurances causing the system overload and, on the other hand, to promote an underestimation of any possible risks (Sijia, Wang, Jia, Nan, \& Tingshao, 2020; Asmundson \& Taylor, 2020b).

It is necessary to consider the future secondary effects of COVID 19 on the general population as any changes in working conditions, physical health compromised by quarantine conditions including the imbalance of biological rhythms that could generate other psychiatric disorders such as depression and anxiety. Nevertheless, many studies (Islam, 2020; Hawkins, 2020; Stewart, 2020) suggest the outbreak of a huge economic crisis after lockdown period, with a strong decrease of Gross Domestic Product and employment (especially for people with short-term contracts in the economic fields most affected by lockdown measures, such as tourism, cultural goods, arts and leisure..). Finally, since health personnel is the one now employed in the front line, it would be necessary a period of abstention from work for them; thus, health personnel strengthening will be needful and, probably, specific psychological interventions for them, in case they developed a sense of helplessness.

All these cases could worsen the already critical world economic situation and need to be faced with accuracy and expertise.

\section{Take home message}

Given that mental health can play a fundamental role in the management of this emergency, it would be appreciable that, not only the mental health services but the main referents of the Institutions, such as the presidents of the nations and the Ministers of health, also pay attention to prevention by mentioning the importance of taking care of the mental health and allocating funds to enhance mental health services.

At this moment the main offices that govern countries need to direct the whole population to take care of their mental health for the good of the community and the economy.

\section{References}

American Psychiatric Association. (2013). Diagnostic and Statistical Manual of Mental Disorders, Fifth Edition, DSM-5.. Washington, DC: APA.

Asmundson, G. J. G., \& Taylor, S. (2020a). Coronaphobia: Fear and the 2019-nCoV outbreak. Journal of Anxiety Disorders, 70.

Asmundson, G. J. G., \& Taylor, S. (2020b). How health anxiety influences responses to viral outbreaks like COVID-19: What all decision-makers, health authorities, and health care professionals need to know. J Anxiety Disord, 71.

Baig, A. M., Khaleeq, A., Ali, U., \& Syeda, H. (n.d.). Evidence of the COVID-19 Virus Targeting the CNS: Tissue Distribution, Host-Virus Interaction, and Proposed Neurotropic Mechanisms. Available on https://doi.org/10.1021/acschemneuro.0c00122 
Brooks, S. K., Webster, R. K., Smith, L. E., Woodland, L., Wessely, S., \& Greenberg, N. (2020). The psychological impact of quarantine and how to reduce it: rapid review of the evidence.. Lancet Psychiatry, 395, 912-920.

Chen, Q., Liang, M., Li, Y., Guo, J., Fei, D., Wang, L., \& He, L. (2020). Mental health care for medical staff in China during the COVID-19 outbreak. Lancet Psychiatry, 7, 15-16.

Chen, Q., Liang, M., Li, Y., Li, Z., Ge, J., Yang, M., Bi, J et al. (2020). Vicarious traumatization in the general public, members, and non-members of medical teams aiding in COVID-19 control. Brain Behav Immun, 20.

CNOP. (n.d.). Vademecum psicologico coronavirus per i cittadini - Perché le paure possono diventare panico e come proteggersi con comportamenti adeguati, con pensieri corretti e emozioni fondate. Disponibile da https://www.psy.it/gli-psicologi-sul-coronavirus

Duan, L., \& Zhu, G. (2020). Psychological interventions for people affected by the COVID-19 epidemic.. Lancet Psychiatry, 7, 300-302.

Hawkins, John. "How will the coronavirus recession compare with the worst in Australia's history?". The Conversation. Retrieved 16 April 2020.

Huang, J. Z., Han, M. F., Luo, T. D., Ren, A. K., \& Zhou, X. P. (2020). Mental health survey of 230 medical staff in a tertiary infectious disease hospital for COVID-19. Chinese Journal of Industrial Hygiene and Occupational Diseases, 38, 001. https://doi.org/10.3760/cma.j.cn121094-20200219-00063

Kang, L., Li, Y., Hu, S., Chen, M., Yang, C., Xiang Yang, B.,et al. (2020). The mental health of medical workers in Wuhan, China dealing with the 2019 novel coronavirus. Lancet Psychiatry, 7, 14.

Islam, Faisal (20 March 2020). "Coronavirus recession not yet a depression". BBC News. Retrieved 16 April 2020.

Li, Y. C., Bai, W. Z., \& Hashikawa, Y. (2020). The neuroinvasive potential of SARS-CoV2 may play a role in the respiratory failure of COVID-19 patients. J Med Virol., https://doi.org/10.1002/jmv.25728

Liebrenz, M., Bhugra, D., Buadze, A., \& Schleifer, R. (2020). Caring for persons in detention suffering with mental illness during the Covid-19 outbreak. Forensic Science International: Mind and Law, 1.

National Health Commission of China. (n.d.). [A notice on the issuance of guidelines for emergency psychological crisis intervention in pneumonia for novel coronavirus infections.]. Disponibile da http://www.nhc.gov.cn/xcs/zhengcwj/202001/6adc08b966594253b2b791be5c3b9467.shtml

Ostuzzi, G., Amaddeo, F., Michencigh, G., Fagiolini, A., Imperadore, G., \& Barbui, C. (n.d.). Indicazioni pratiche sull'uso degli psicofarmaci in pazienti affetti da COVID-19psychological crisis intervention in pneumonia for novel coronavirus infections.. Disponibile da https://siep.it/psicofarmaci-e-covid-19/

Shigemura, J., Ursano, R. J., Morganstein, J. C., Kurosawa, M., \& Benedek, D. M. (2020). Public responses to the novel 2019 coronavirus $(2019-\mathrm{nCoV})$ in Japan: Mental health consequences and target populations.. Psychiatry ClinNeurosci, . https://doi.org/10.1111/PCN.12988

Sijia, L., Wang, Y., Jia, X., Nan, Z., \& Tingshao, Z. (2020). The Impact of COVID-19 Epidemic Declaration on Psychological Consequences: A Study on Active Weibo Users.. Int. J. Environ. Res. Public Health, 17, 2032.

Silva, M., Resurrección, D. M., Antunes, A., Frasquilho, D., \& Cardoso, A. (2018). Impact of economic crises on mental health care: a systematic review.. EpidemiolPsychiatr Sci.

Stewart, Emily (21 March 2020). "The coronavirus recession is already here". Vox. Retrieved 16 April 2020. 
Taylor, A. S. W., \& Frazer, A. G. (1981). Psychological sequelae of operation overdue following the DC 10 aircrash in Antartica.. Victoria, US: Department of Psychology, Victoria University of Wellington.

Wang, C., Pan, R., Wan, X., Tan, Y., Xu, L., \& Ho, C. S. et al. (2020). Immediate Psychological Responses and Associated Factors During the Initial Stage of the 2019 Coronavirus Disease (COVID-19) Epidemic Among the General Population in China. J. Environ. Res. Public Health, 17.

World Health Organization. (n.d.-a). [Novel coronavirus emerges in China]. Disponibile da Novel coronavirus emerges in China. http://www.euro.who.int/en/health-topics/health-emergencies/coronaviruscovid19/news/news/2020/01/novel-coronavirus-emerges-in-china

World Health Organization. (n.d.-b). [COVID-19 situation update for the WHO European Region.]. http://www.euro.who.int/en/health-topics/health-emergencies/coronavirus-covid-19/weekly-surveillancereport

Figure 1

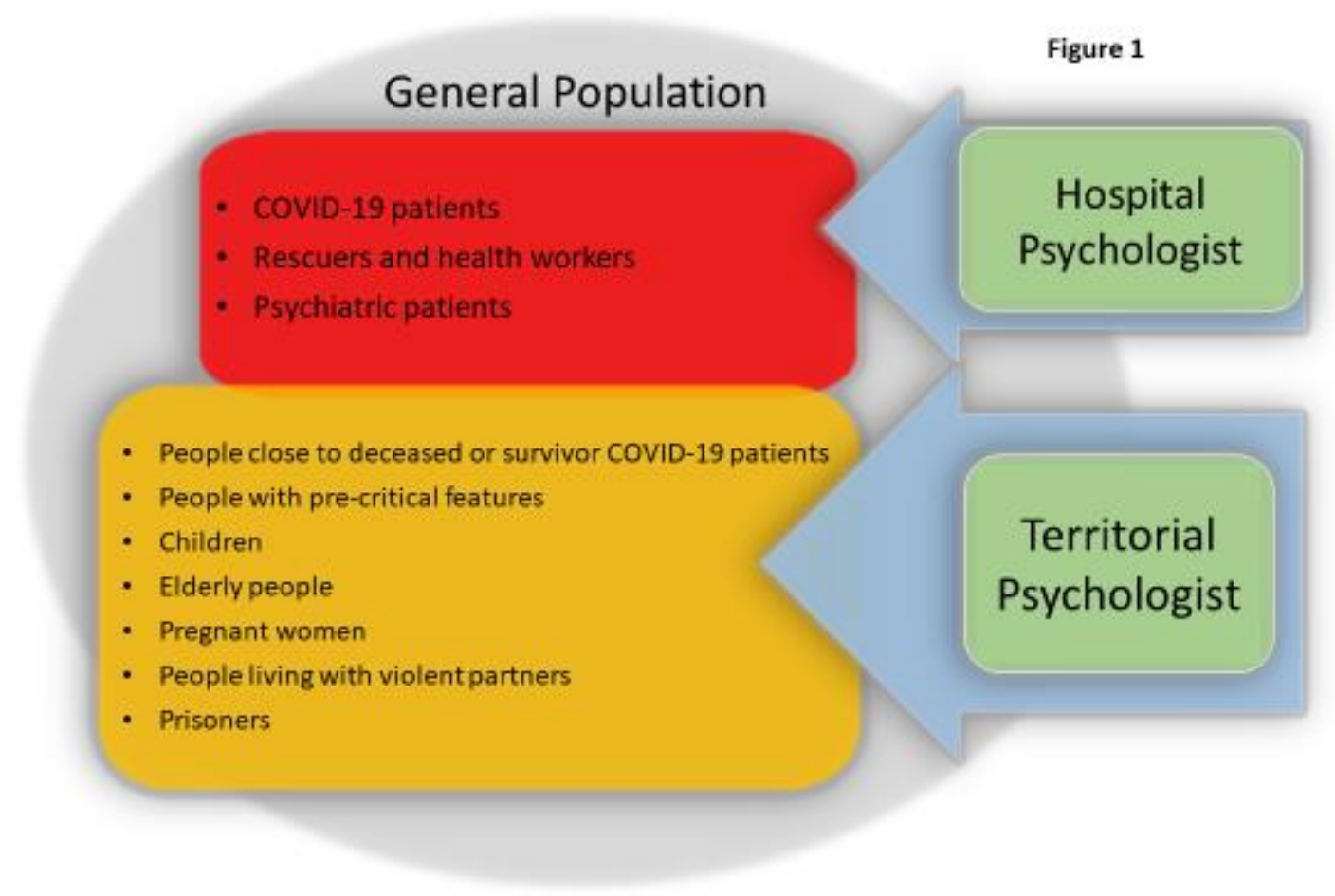


Word count 2834 